Gut, 1972, 13, 176-181

\title{
Gastric emptying of solid meals after truncal vagotomy and pyloroplasty in human subjects
}

\author{
D. J. COWLEY, ${ }^{1}$ P. VERNON, T. JONES, H. I. GLASS, AND A. G. COX ${ }^{2}$
}

From the Departments of Surgery, Medical Physics, and the MRC Cyclotron Unit, Royal Postgraduate Medical School, Hammersmith Hospital, London

SUMMARY Gastric emptying of isotopically labelled solid meals was studied in normal human subjects and in patients at different intervals after truncal vagotomy and Heineke-Mikulicz pyloroplasty.

One to four weeks after vagotomy and pyloroplasty gastric emptying was delayed grossly in some patients regardless of the completeness of vagotomy. Patients with gross delay had symptoms of gastric retention. Eight weeks later emptying had returned towards normal and one or more years after vagotomy and pyloroplasty emptying was within the normal range.

A subthreshold dose of carbachol injected during the course of emptying of a meal in some of the postvagotomy patients had no detectable influence on the rate of emptying of the meal.

Symptoms of gastric retention are common in patients who have recently had a truncal vagotomy and pyloroplasty (Williams and Barnes, 1969). Retention is a major problem after vagotomy alone (Dragstedt, Harper, Tovee, and Woodward, 1947) and even with the addition of a drainage procedure the incidence may be as high as $17 \%$ (Barnes and Williams, 1967). Dragstedt and his coworkers observed that the symptoms improved with time and attributed this to the return of tone to the vagally denervated stomach.

Recently, Tinker, Kocak, Jones, Glass, and Cox (1970) found that gastric emptying of solid meals was delayed in patients tested less than a month after truncal vagotomy and pyloroplasty. When the same patients were given a subthreshold dose of carbachol intravenously before they ate the meal gastric emptying was significantly accelerated. They postulated that the vagotomized stomach is supersensitive to cholinergic stimuli and thus obeys Cannon's law of denervation (Cannon, 1939). They suggested that if this applied only to patients whose vagotomy was complete it might provide the basis of a test for completeness of vagotomy.

We decided to study these phenomena further by measuring gastric emptying of solid meals, labelled with a radioisotope, in patients at different time

${ }^{1}$ Present address: Department of Surgery University Hospital of South Manchester, West Didsbury, Manchester.

'Present address: Division of Surgery, Northwick Park Hospital and Clinical Research Centre, Harrow, Middx.

Received for publication 1 December 1971. intervals after truncal vagotomy and pyloroplasty. We gave a subthreshold dose of carbachol to some of these patients midway through the recording of the emptying of the meal to determine whether it had any effect on the emptying rate of the stomach.

\section{Materials and Methods}

Four groups of human subjects were studied (Table I). There was a control group of volunteers

\begin{tabular}{ll}
\hline Group & No. in Each \\
\hline Healthy volunteers & 10 \\
After truncal vagotomy and pyloroplasty & $\left\{\begin{array}{lc}1-4 \text { weeks }^{1} & 14 \\
1-4 \text { months } & 9 \\
>12 \text { months } & 7\end{array}\right.$ \\
\hline
\end{tabular}

Table I Patients studied

${ }^{1}$ Mean 16 days

${ }^{2}$ Mean 73 days

with no history of gastrointestinal disease. Three groups of patients were tested at different time intervals after truncal vagotomy and a HeinekeMikulicz pyloroplasty for chronic duodenal ulcer: one to four weeks, one to four months, and more than one year. Some of the patients tested at one to four weeks were also studied at the later time intervals, but no patient was tested more than twice and the analysis of results was for unpaired groups of subjects. 
MEASUREMENT OF GASTRIC EMPTYING

The method was similar to that described by Jones, Clark, Kocak, Cox, and Glass (1970) but modified to allow continuous recording of gastric radioactivity on magnetic tape. The patient, who had fasted for 12 hours, ate a meal of two scrambled eggs, two slices of buttered bread, a spoonful of jam, and $300 \mathrm{ml}$ of milk. One hundred microcuries of Caesium 129, adsorbed on to zirconium phosphate, was stirred into the milk. The radiation dose to the colon, the organ which received the highest dose, was 370 millirads but the associated dose to the bone marrow was only 4 millirads. This can be compared with a radiation dose of 1062 millirads to the bone marrow during a barium enema investigation (Report of Committee on Radiological Hazards to Patients, 1966). This radiation dose after Caesium 129 is significantly lower than the dose associated with other, longer-lived isotopes.

After finishing the meal the patient lay supine under a gamma camera and was manoeuvred until the whole of the stomach, as depicted by the tracer, lay centrally in the field of view displayed on an oscilloscope. As soon as positioning was completed recording of the radioactivity in the field viewed by the gamma camera was begun and the information stored continuously on magnetic tape. The mean time interval from the subject beginning to eat the meal to the start of the recording was $11.2+3.9 \mathrm{SD}$ minutes. There were no significant differences between the groups studied. The recording was carried out for 90 minutes.

The tape was later processed by a CDC 6600 computer, using a specially written program which gave a static output representing the field

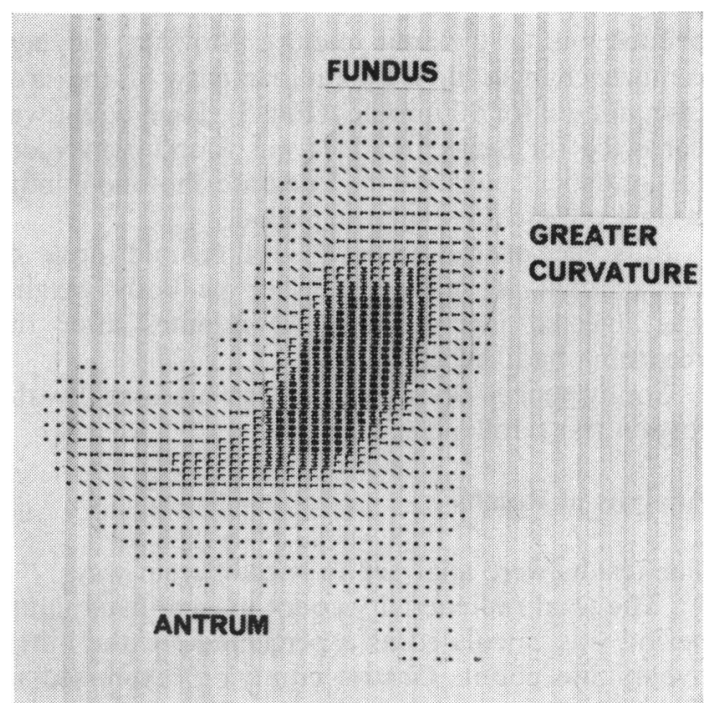

Fig. 1 Static printout of the area scanned by the gamma camera in one normal subject. The stomach shows as an area of relatively high count rate. The grid references at margins are not shown.

viewed by the camera (Vernon and Glass, 1971a, 1971b). Using the first two and half minutes of recorded data the stomach was shown as a well defined area in the centre of the field and the boundaries of this area were delineated from a gridreference system marked out on this printed sheet (Fig. 1). The figures delineating the area were punched onto data cards and fed back into the computer with the tape. The computer, thus instructed to view only the gastric area of the field,

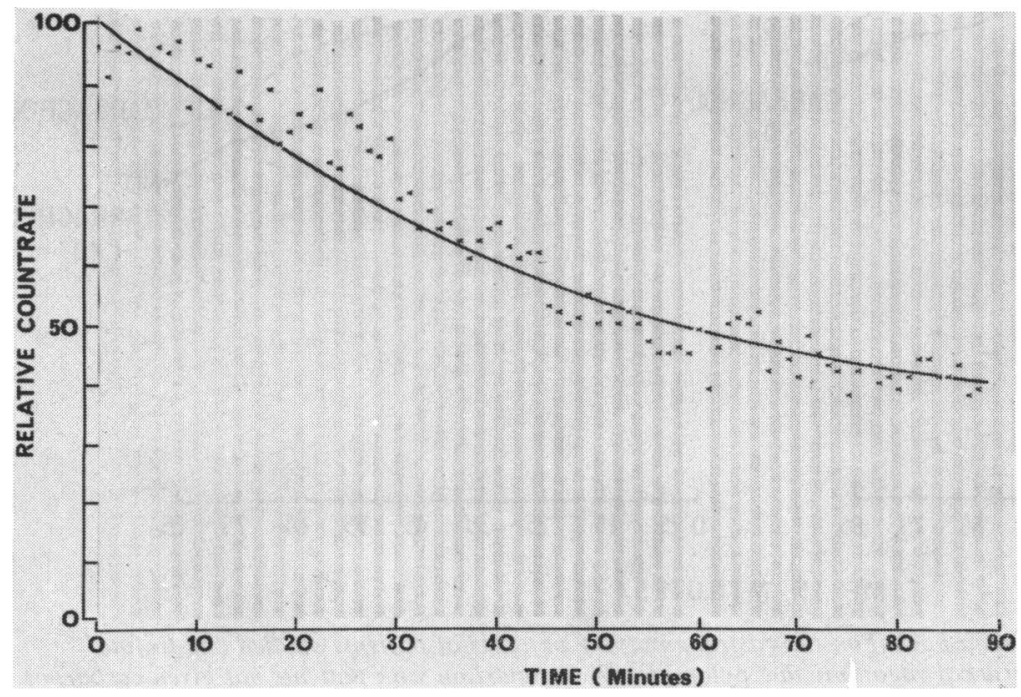

Fig. 2 Dynamic printout showing emptying pattern of stomach in Figure 1. Count rate per minute is usually shown at top of chart, time in seconds at bottom. 
printed out a dynamic picture showing the percentage changes in total radioactivity of the area each minute for 90 minutes (Fig. 2). Each count was corrected for background. It was found convenient for statistical purposes to integrate the one-minute counts for each five-minute period.

In some of the tests a subthreshold dose of carbachol $(0.06$ micrograms per $\mathrm{kg}$ body weight) was injected intravenously 40 minutes after the recording had been started.

Completeness of vagotomy was assessed by the insulin test (Hollander, 1948).

\section{Analysis of Results}

The results were analysed in two different ways:

1 The total radioactivity count in each five-minute period was calculated as a percentage of the initial five-minute count. Gastric emptying, expressed as this percentage, was calculated at five minutes and then at 10-minute intervals to 85 minutes after the initial count. Mean percentage gastric emptying at these time intervals was calculated for the different groups under study.

2 In order to study and compare results in individual patients, the half emptying time ( $\left.T \frac{1}{2}\right)$ was calculated. The regression equation for $\log _{10}$ of counts for five minutes $(y)$ against time $(x)$ was calculated. The time in minutes for the stomach to empty by half $\left(\mathrm{T} \frac{1}{2}\right)$ was found from the regression line. To determine whether emptying was monoexponential during the 90 -minute test period, the $\mathrm{T}_{\frac{1}{2}}$ was calculated for the 0-40- and 45-90-minute periods separately. Analysis by a paired t test revealed no significant differences between the mean $\mathrm{T} \frac{1}{2} \mathrm{0}-40$ and $\mathrm{T} \frac{1}{2}$ 45-90 in any of the groups (see Table II). A monoexponential emptying pattern was therefore assumed both for normal subjects and for patients after vagotomy. There were individual exceptions to this rule but no trend could be discerned.

\section{Results}

\section{EFFECT OF CARBACHOL}

Seven of the eight patients who received carbachol had had a complete vagotomy. The patterns of gastric emptying (Fig. 3) and $\mathrm{T} \frac{1}{2}$ values (Table II) were not changed by the administration of a subthreshold dose of carbachol. Therefore, the results of all tests were used for analysis according to the clinical group of the patient and irrespective of the administration or otherwise of carbachol.

\section{\% GASTRIC EMPTYING

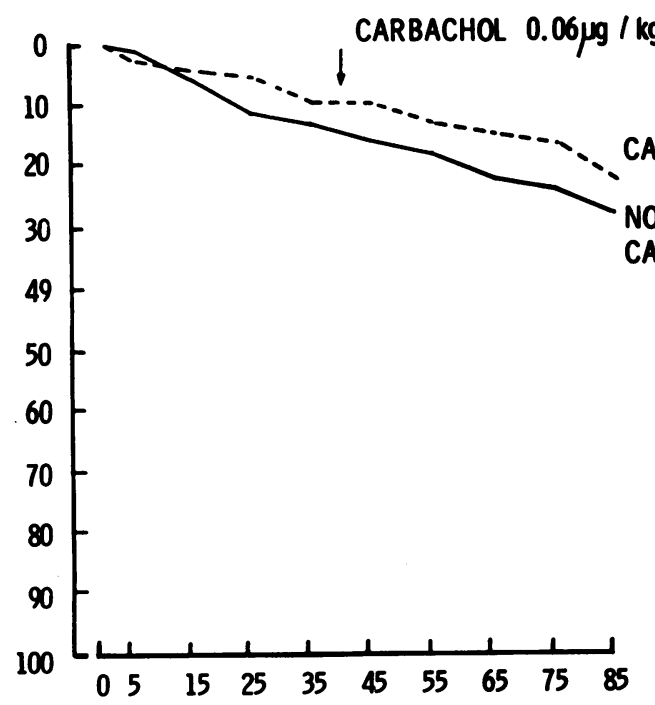

kg I. V.

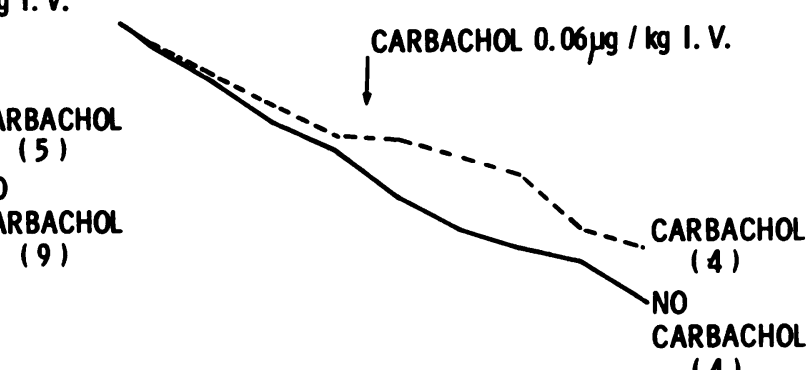

TIME IN MINUTES

Fig. 3 Lack of effect of subthreshold carbachol on the gastric emptying patterns of patients studied one to four weeks and one to four months after truncal vagotomy and pyloroplasty. Comparison with patients not given carbachol. 


\begin{tabular}{|c|c|c|c|c|}
\hline \multirow[t]{2}{*}{ Group } & \multirow[t]{2}{*}{$n$} & \multicolumn{2}{|c|}{$T \frac{(\min )}{} \pm S E M$} & \multirow{2}{*}{$\begin{array}{l}\text { Exact } \\
P\end{array}$} \\
\hline & & $0-40$ & $45-90$ & \\
\hline $\begin{array}{l}\text { Volunteers } \\
1-4 \text { weeks } \\
1-4 \text { months } \\
>12 \text { months } \\
\text { All postvagotomy } \\
\text { No carbachol }\end{array}$ & $\begin{array}{c}10 \\
12^{1} \\
8^{1} \\
7 \\
16\end{array}$ & $\begin{array}{r}95 \pm 12 \\
552 \pm 284 \\
205 \pm 74 \\
133 \pm 26 \\
157 \pm 21\end{array}$ & $\begin{array}{l}119 \pm 24 \\
368 \pm 107 \\
114 \pm 8 \\
140 \pm 30 \\
164 \pm 25\end{array}$ & $\begin{array}{l}0.25 \\
0.55 \\
0.26 \\
0.88 \\
0.82\end{array}$ \\
\hline All with carbachol & 11 & $272 \pm 74$ & $252 \pm 109$ & 0.85 \\
\hline
\end{tabular}

Table II Comparison of half-emptying times in first and second halves of test

'Other patients recorded for 75 minutes

\section{PATTERNS OF GASTRIC EMPTYING AFTER VAGOTOMY}

In Fig. 4, the mean percentage gastric emptying patterns of the three postvagotomy groups have been plotted for comparison with the control group. One to four weeks after vagotomy gastric emptying was consistently and significantly slower than emptying in the controls. One to four months after vagotomy emptying was still slower than in the controls but the differences were much less and statistically significant only at the end of the test. One to three years after vagotomy the difference between the postoperative and control groups had disappeared.

\section{HALF-EMPTYING TIMES}

The $T \frac{1}{2}$ of the individual patients is illustrated in Figure 5, which shows also the results in those patients who had tests at different stages after vagotomy. Inspection of this illustration reveals that the slower mean emptying time one to four weeks after vagotomy was associated with a very wide scatter of results with gross delay in some patients and results within the normal range in others. Gross delay was not related to the completeness or otherwise of the vagotomy as judged by the insulin test. One to four months after vagotomy substantial recovery had occurred in patients who exhibited gross delay one to four weeks after vagotomy. One year or more after vagotomy, only one patient had a $T_{\frac{1}{2}}$ outside the normal range (all patients in this group had a complete vagotomy).

Symptoms of gastric retention in the 14 patients tested one to four weeks after vagotomy correlated well with the results of the gastric emptying tests. Five patients had gross delay with a $T_{2}^{\frac{1}{2}}$ greater than 400 minutes; all complained of troublesome fullness after meals, two had episodes of vomiting, and one had frequent hiccups. One of three patients with a $\mathrm{T} \frac{1}{2}$ of 200 to 250 minutes had fullness after meals, and of six patients with a $\mathrm{T} \frac{1}{2}$ of 85 to 175 minutes only one had slight fullness after meals.

\section{1-4 weeks after vagotomy (14)}

\section{1-4 months after} vagotomy (9)
1-3 years after vagotomy (7)
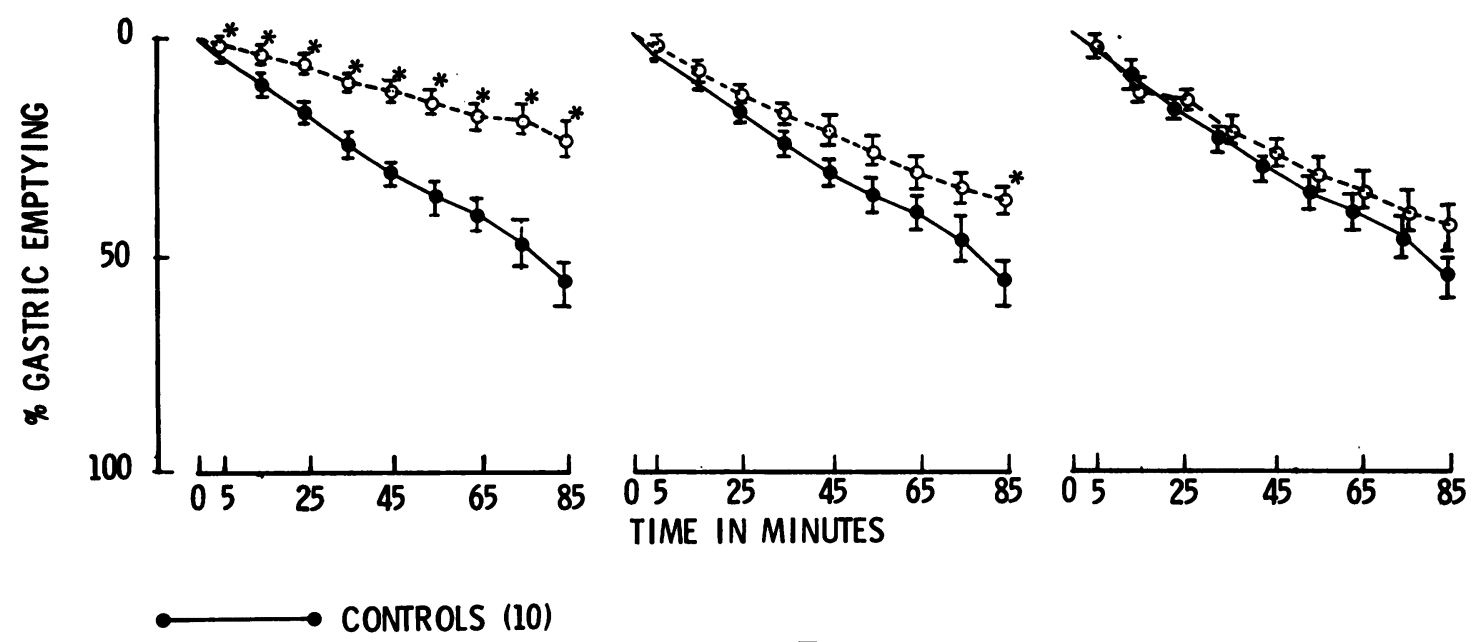

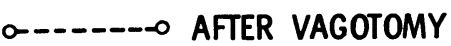

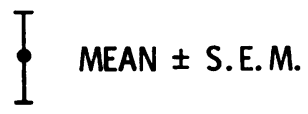

* $P<0.01$

Fig. 4 Comparisons of gastric emptying pattern at different time intervals after vagotomy with normal gastric emptying pattern. 
$T \frac{1}{2}$ ( MINUTES)

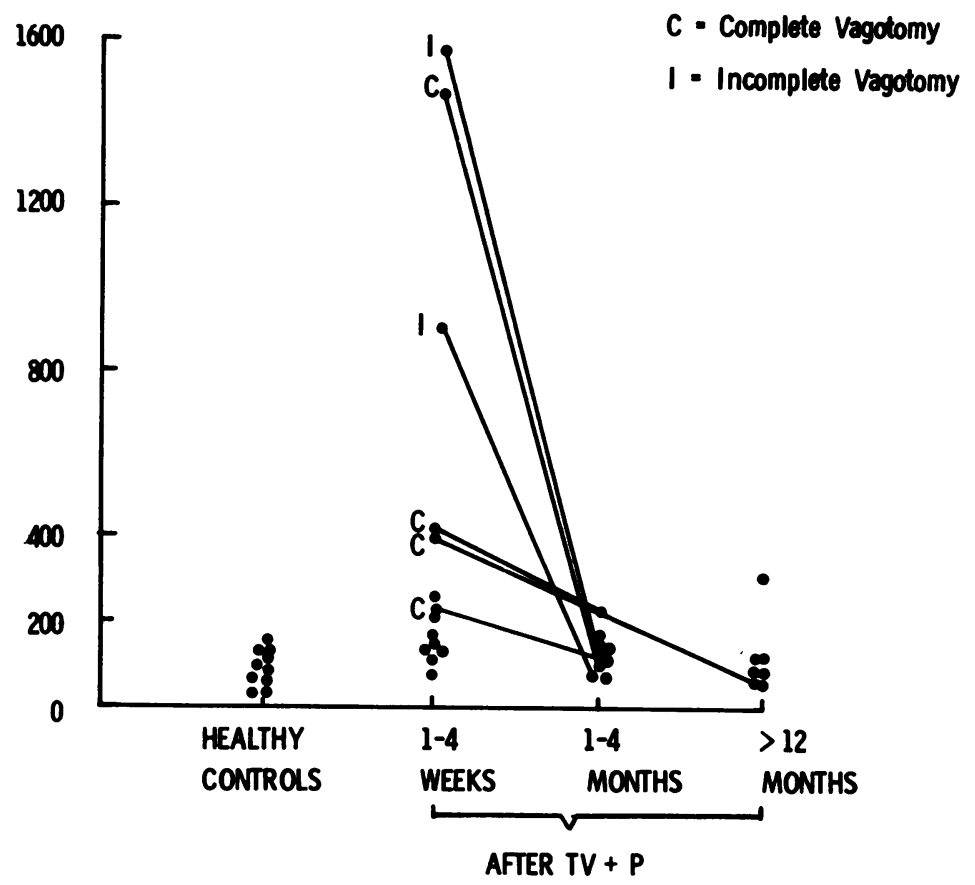

Fig. 5 Half-emptying time $\left(T_{2}\right)$ of individual subjects in the different groups. Six patients had a second test after an interval of time.

\section{Discussion}

A subthreshold dose of carbachol injected half-way through the period of measurement had no detectable influence on the rate of emptying of the meal in patients after vagotomy. Therefore this method, based on the concept of supersensitivity, could not be used to distinguish patients with complete and incomplete vagotomy. This finding does not necessarily negate the suggestion of Tinker et al (1970) that this approach might provide an alternative to the insulin test, because we studied the patients in a different way. Tinker and his colleagues did two separate tests, one with and the other without carbachol, whereas we did a single test in the hope that we could spare the patient a second visit to the hospital.

An alternative explanation for the difference between our findings and those of Tinker et al (1970) might be that their second test was sometimes done after an interval of up to three weeks. We have found that spontaneous recovery in the rate of emptying may occur during this period.

A temporary delay in the gastric emptying of solid meals was observed in patients with duodenal ulcer after truncal vagotomy and pyloroplasty. The delay was followed by recovery to normal within three months. Tinker et al (1970) and Griffith, Owen, and
Shields (1966a) also found this delay in gastric emptying shortly after truncal vagotomy and pyloroplasty but they did not investigate the possibility that recovery takes place. In the present study, the group studied one to four weeks after vagotomy showed a statistically significant delay in emptying compared with the healthy controls, but there were great differences between individuals in the group. Some exhibited gross delay in emptying while the emptying times of others were within the normal range. Gross delay was associated with the symptoms of gastric retention. Delay occurred regardless of whether the vagotomy was complete or incomplete; some patients with incompletely vagotomized stomachs emptied very slowly and others with a complete vagotomy emptied rapidly. Thus, in order to explain this phenomenon of a temporary delay of emptying in certain patients a factor other than vagal denervation of the stomach must be postulated. This factor might be a paradoxical narrowing at the pyloroplasty. All of the present group had a Heineke-Mikulicz pyloroplasty. This was closed with two layers of sutures in 10 patients and with one layer in four patients. The length of the pyloroplasty incision was not often measured at operation and it is therefore impossible to determine retrospectively the reason for a temporary postoperative narrowing. Griffith, Owen, Kirkman, and 
Shields (1966b) showed some evidence that emptying is more rapid after a vagotomy and Finney pyloroplasty than after a vagotomy and Heineke-Mikulicz pyloroplasty. A prospective controlled trial of the two types of pyloroplasty could resolve this point.

Buckler (1967) studied the emptying of semi-solid meals in patients who had undergone various types of gastric surgery. He found that a simple pyloroplasty produced a delay in emptying compared with controls. When it was combined with truncal vagotomy still greater delay ensued. McKelvey, Connell, and Kennedy (1970) studied the emptying of liquid meals after vagotomy and pyloroplasty and found that emptying varied according to the posture of the patient; lying on the left side was associated with very slow emptying, lying on the right side with very rapid emptying. They concluded that the vagotomized stomach behaves as an 'incontinent organ'.

In the present study we have attempted to keep all the factors involved in measuring gastric emptying constant for every patient, thus posture is unlikely to account for differences between the groups. We have used a solid meal and whilst it is possible that this empties differently from liquids we have not attempted to study the effect of different postures.

The authors wish to thank Miss Diane Whait, Mrs Penny Shilling, and Miss Anne Morash for technical assistance and Miss Stephanie Nichols for secretarial help.
References

Barnes, A. D., and Williams, J. A. (1967). Stomach drainage after vagotomy and pyloroplasty. Amer. J. Surg., 113, 494-497.

Buckler, K. G. (1967). Effects of gastric surgery upon gastric emptying in cases of peptic ulceration. Gut, 8, 137-147.

Cannon, W. B. (1939). A law of denervation. Amer. J. med. Sci., 198, 737-750.

Dragstedt, L. R., Harper, P. V., Jr., Tovee, E. B., and Woodward, E. R. (1947). Section of the vagus nerves to the stomach in the treatment of peptic ulcer: complications and end results after four years. Ann. Surg., 126, 687-699.

Griffith, G. H., Owen, G. M., and Shields, R. (1966a). The rate of gastric emptying in gastroduodenal disease. (Abstr.) Brit. J. Surg., 53, 995.

Griffith, G. H., Owen, G. M., Kirkman, S., and Shields, R. (1966b). Measurements of rate of gastric emptying using chromium 51. Lancet, 1, 1244-1245.

Hollander, F. (1948). Laboratory procedures in the study of vagotomy (with particular reference to the insulin test). Gastroenterology, $11,419-425$.

Jones, T., Clark, J. C., Kocak, N., Cox, A. G., and Glass, H. I. (1970). Measurement of gastric emptying using the scintillation camera and ${ }^{129} \mathrm{Ca}$. Brit. J. Radiol., 43, 537-541.

McKelvey, S. T. D., Connell, A.M., and Kennedy, T. L. (1969). Gastric emptying and transit time as factors in postvagotomy diarrhoea. Gut, $10,1047$.

Ministry of Health and Scottish Home and Health Department (1966). (Final Report of Committee) Radiological Hazards to Patients. H.M.S.O., London.

Tinker, J., Kocak, N., Jones, T., Glass, H. I., and Cox, A. G. (1970). Supersensitivity and gastric emptying after vagotomy. Gut, 11, 502-505.

Vernon, P., and Glass, H. I. (1971a). An off-line digital system for use with a gamma camera. Phys. med. Biol., 16, 405-415.

Vernon, P., and Glass, H. I. (1971b). Processing gamma camera data obtained from an off-line system. In Dynamic Studies with Radioisotopes in Medicine, pp. 133-143. International Atomic Energy Agency, Vienna.

Williams, J. A., and Barnes, A. D. (1969). Post-operative gastric retention. In After Vagotomy, edited by J. A. Williams and A. G. Cox, ch. 14. Butterworths, London. 